\title{
Role of segmental colonic transit time studies to select patients with slow transit constipation for partial left-sided or subtotal colectomy
}

\author{
E. J. R. DE GRAAF, E. C. A. M. GILBERTS and W. R. SCHOUTEN
}

Department of General Surgery, University Hospital Rotterdam, Rotterdam, The Netherlands

Correspondence to: Dr E. J. R. de Graaf, Department of General Surgery, IJsselland Ziekenhuis, Prins Constantijnweg 2, 2906 ZC Capelle aan de IJssel, The Netherlands

This prospective study investigated the value of segmental colonic transit time studies in the surgical treatment of slow transit constipation. Overall, 346 patients with chronic constipation were analysed; slow transit constipation was diagnosed in 86 ( 25 per cent). Based on the results of segmental colonic transit time studies, 18 patients underwent partial left-sided colectomy and 24 subtotal colectomy. Recurrent constipation was seen in three of 18 patients and seven of 24 respectively. Severe abdominal discomfort was noted in six of 18 and 15 of 24 respectively. Disabling diarrhoea and faecal incontinence developed in two of 14 and five of 20 patients with an anastomosis respectively. Although these results indicate that segmental colonic transit time studies are useful in selecting patients with slow transit constipation for partial left-sided or subtotal colectomy, both procedures should be performed with prudence.
Patients with slow transit constipation have infrequent defaecation with two or fewer bowel actions each week. Although they have a normal-sized colon, the colonic transit time is markedly prolonged. Most patients present with a general sense of malaise, bloating, abdominal pain, nausea and vomiting, which interferes with the ability to work and to enjoy social activities. Dietary measures and medical treatment including laxatives and enemas fail to relieve these distressing symptoms. This syndrome is confined almost entirely to women ${ }^{1}$. Subtotal colectomy is advocated when conservative measures have failed and surgical intervention is finally considered ${ }^{2-4}$.

There are embryological, histological and functional differences between the right and left parts of the colon ${ }^{5}$. Furthermore, isolated left-sided colonic dysfunction following surgery for rectal cancer and after spinal cord injuries has been reported ${ }^{6,7}$. Segmental colonic transit time studies are advocated to distinguish between patients with total colonic inertia, left-sided colonic inertia and anorectal outlet obstruction ${ }^{8-10}$. Despite these facts, no prospective study has been performed using segmental colonic transit times to select patients for partial colectomy.

This prospective study investigated the role of segmental colonic transit times in the decision-making process before surgery for slow transit constipation and compared the results of partial left-sided colectomy with those of subtotal colectomy.

\section{Patients and methods}

Between May 1985 and December 1994, 346 patients with severe long-standing constipation and disordered defaecation were analysed according to a standard protocol. This protocol included the patient's history, results of physical, biochemical and endoscopic examination, findings at barium enema, anorectal manometry, full-thickness rectal biopsy, electromyography of the pelvic floor, defaecography and segmental colonic transit time studies. To determine segmental colonic transit time the method described by Arhan et al. ${ }^{11}$ was used. From at least 2 days before the start of the transit time study,

Paper accepted 1 October 1995 patients stopped taking laxatives, enemas, prokinetic agents and any other drug that could possibly influence colonic transit. No dietary changes were made. Subtotal colectomy was advised when the progression of markers was delayed in all segments of the large bowel and partial left-sided colectomy when transit in the right part of the colon was normal.

Slow transit constipation was diagnosed in 86 patients ( 25 per cent). Forty-eight patients with such constipation underwent colonic resection. Four patients were followed up for less than 12 months. A further patient needed a terminal ileostomy after breakdown of the ileorectal anastomosis. One patient died shortly after the operation from mesenteric infarction. The remaining 42 patients, 40 women and two men of mean age at operation 47 (range 17-73) years, were available for follow-up of at least 1 year. The mean follow-up was 46 (range 12-80) months.

Before operation all patients were constipated with a median interval between spontaneous bowel movements of 20 days (range 3 days to no defaecation at all), of 7 days between bowel movements with the help of laxatives (range 3 days to no defaecation at all) and of 7 days between bowel movements with the help of enemas (range 1 day to no defaecation at all). All patients had used a variety of laxatives and 21 had used enemas regularly. Clinical features are shown in Table 1. The median duration of symptoms was 18 (range 1-70) years.

At follow-up, patient satisfaction was assessed and functional results classified according to the system shown in Table 2. In patients with an anastomosis, recurrent constipation was defined

Table 1 Clinical features before and after colonic resection for slow transit constipation

\begin{tabular}{lllc}
\hline & & \multicolumn{2}{c}{ After colectomy } \\
\cline { 3 - 4 } & $\begin{array}{l}\text { Before } \\
\text { operation } \\
(n=42)\end{array}$ & $\begin{array}{l}\text { Partial } \\
\text { left-sided } \\
(n=18)\end{array}$ & $\begin{array}{c}\text { Subtotal } \\
(n=24)\end{array}$ \\
\hline Constipation & 42 & 3 & 7 \\
Use of laxatives & 42 & 3 & 5 \\
Use of enemas & 21 & 0 & 0 \\
Abdominal pain & 38 & 6 & 15 \\
Nausea & 29 & 4 & 12 \\
Vomiting & 22 & 2 & 10 \\
Bloating & 34 & 4 & 12 \\
Disabling diarrhoea & 0 & 1 & 3 \\
Faccal incontinence & 0 & 1 & 2 \\
\hline
\end{tabular}


as a stool frequency of less than two a week. In patients with a stoma, recurrent constipation was defined as irregular non-daily production of faeces. Regular use of laxatives and enemas was also considered to be a sign of recurrent constipation. Daily incapacitating abdominal pain, bloating, nausea and vomiting were classified as severe abdominal discomfort. Recurrent constipation, severe abdominal discomfort as well as disabling diarrhoea and faecal incontinence were considered as failures. Abdominal complaints not interfering with daily life and occurring less than once a week were defined as mild abdominal discomfort and not classified as a failure (Table 2).

\section{Results}

Based on the results of segmental colonic transit time studies, 18 patients underwent partial left-sided colectomy and 24 subtotal colectomy. A primary anastomosis was constructed in 14 patients after partial left-sided colectomy and in 20 after subtotal colectomy. An end stoma was created in the remaining patients, who had poor anal function. Postoperative clinical features are shown in Table 1. Recurrent constipation was seen in three of 18 patients following left-sided colectomy and in seven of 24 after subtotal colectomy. Postoperative disabling diarrhoea and faecal incontinence occurred in respectively two of 14 and five of 20 patients who had an anastomosis (Table 3). In patients who developed recurrent constipation, the symptoms recurred in 80 per cent within 1 year of the operation. Severe abdominal discomfort recurred within 15 months in 90 per cent of those affected (Figs 1 and 2).

After partial left-sided colectomy and subtotal colectomy 12 of 18 patients and 15 of 24 respectively expressed satisfaction with the outcome.

Table 2 Scoring system for the evaluation of functional results

\begin{tabular}{llc}
\hline & Success & Failure \\
\hline Recurrent constipation & - & + \\
$\quad$ Stool frequency $<2$ times weekly & & \\
$\quad$ Irregular non-daily stoma production & & \\
Regular use of laxatives & & \\
$\quad$ Regular use of enemas & + & \\
Mild abdominal discomfort & & \\
$\quad$ Mild abdominal complaints occasionally & & \\
$\quad$ Not interfering with daily life & - & + \\
Severe abdominal discomfort & & \\
$\quad$ Bloating, nausea, vomiting & & \\
Daily and disabling abdominal pain & - & + \\
Disabling diarrhoea & - & + \\
Faecal incontinence & & \\
\hline
\end{tabular}

Table 3 Functional results after colonic resection for slow transit constipation

\begin{tabular}{lllll}
\hline & & \multicolumn{3}{c}{ Failures } \\
\cline { 3 - 5 } & Successes & $\begin{array}{l}\text { Recurrent } \\
\text { constipation }\end{array}$ & $\begin{array}{l}\text { Severe } \\
\text { abdominal } \\
\text { discomfort }\end{array}$ & $\begin{array}{l}\text { Disabling } \\
\text { diarrhoea } \\
\text { and faecal } \\
\text { incontinence }\end{array}$ \\
\hline $\begin{array}{l}\text { Colectomy } \\
\text { Partial left- } \\
\text { sided } \\
\text { Subtotal }\end{array}$ & 12 of 18 & 3 of 18 & 6 of 18 & 2 of 14 \\
\hline
\end{tabular}

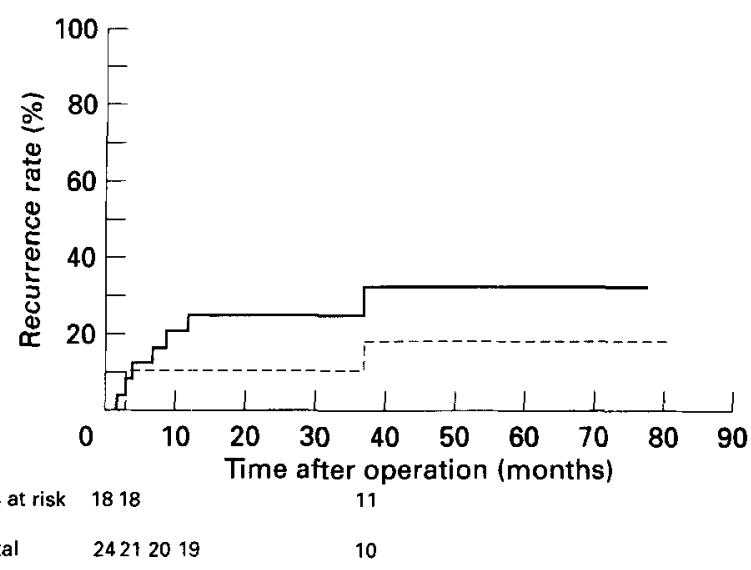

Fig. 1 Recurrent constipation after partial left-sided (- - - ) and subtotal (— colonic resection for slow transit constipation (Kaplan-Meier analysis)

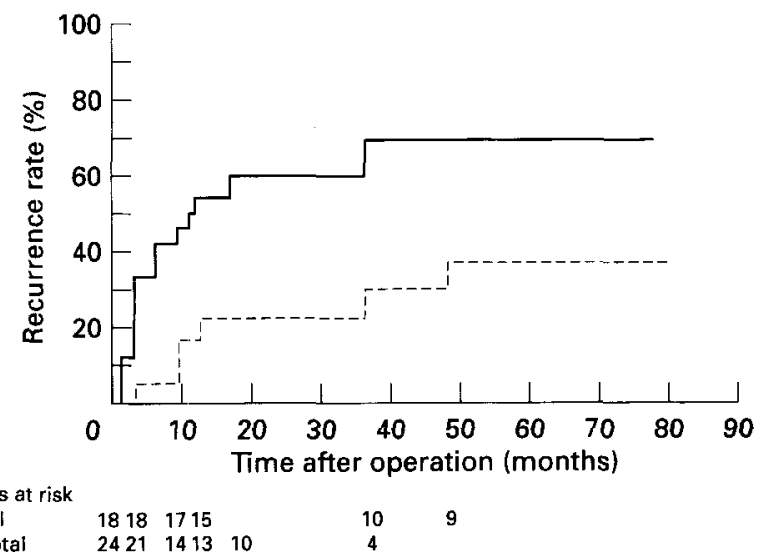

Fig. 2 Severe abdominal discomfort after partial left-sided $(---)$ and subtotal $(-)$ colonic resection for slow transit constipation (Kaplan-Meier analysis)

Small bowel obstruction developed in one patient and required division of adhesions, after which she did well. In one patient repeat laparotomy was performed because of severe abdominal discomfort. During laparotomy mild dilatation of the terminal ileum was observed and a terminal ileostomy was created. After operation there was daily regular stoma production, but the severe abdominal discomfort persisted.

\section{Discussion}

At the beginning of this century, Arbuthnot Lane ${ }^{12}$ was probably the first to perform colectomy with ileorectal anastomosis in patients with slow transit constipation. Initially patients were selected for the operation largely according to the severity of symptoms $s^{3,13-20}$. During the past two decades, whole gut transit time studies, using radio-opaque markers, have been added for selecting possible candidates for surgery ${ }^{2,4,21-34}$. To date over 20 papers have been published on the functional outcome of colonic resection in a total of 443 patients past $^{2-12-34}$. The vast majority (372) of these patients underwent subtotal 
colectomy, which was successful in 289 (78 per cent). In 71 patients partial colectomy was performed with good functional outcome in 57 ( 80 per cent). Although these results are similar, most surgeons perform subtotal colectomy, mainly based on the recommendations of Preston et $a l^{2}$, who concluded that subtotal colectomy was successful in 11 of 16 patients. However, eight of these 16 continued having abdominal pain, ten having bloating and six episodes of faecal incontinence after operation. These symptoms were not included in the evaluation of clinical outcome. Five further patients underwent partial colectomy; in two of these partial left-sided colectomy was performed and in three sigmoid resection. The indication for partial colectomy was not given and none of the patients was selected on the basis of segmental colonic transit time studies. In contrast to the detailed discussion regarding clinical outcome after subtotal colectomy, it was stated only that patients after partial colectomy did not improve. In our opinion, it is remarkable that the recommendation to perform subtotal colectomy is based only on this single study.

Embryologically the proximal part of the colon originates from the midgut and the distal part from the hindgut. The proximal and distal parts are innervated and vascularized in different ways. The right colon has mainly resorptive capacities whereas the left colon has storage capacities $^{5}$. Decreased motility in the left part of the colon has been observed following surgery for rectal cancer and after spinal cord injury ${ }^{6,7}$. A similar motility disorder, restricted to the left part of the colon, has also been reported in patients with slow transit constipation ${ }^{1,35,36}$. These patients could benefit from partial left-sided colectomy, which has the advantage over subtotal colectomy of retaining some storage and resorptive capacity, thereby avoiding diarrhoea.

In 1969 radio-opaque markers were introduced to measure whole gut transit time ${ }^{37}$; segmental colonic transit time can also be estimated with this technique ${ }^{10,38}$. This has been shown to be a reproducible method ${ }^{37,39}$. More recently, radioscintigraphy has been introduced to assess total and segmental colonic transit time ${ }^{11,40}$. It was demonstrated that radioisotope and radio-opaque marker methods gave similar results ${ }^{40}$. Both methods are useful in classifying patients with slow transit constipation as having total colonic inertia, partial left-sided colonic inertia or anorectal outlet obstruction ${ }^{8-10,40}$. Previously segmental colonic transit time studies have been used only to exclude patients with anorectal outlet obstruction. Surprisingly however, only in one retrospective study were segmental colonic transit time studies used to select two patients for partial left-sided colectomy; both patients improved $^{24}$. In two other reports the results of segmental colonic transit time studies are mentioned. However, in all patients subtotal colectomy was performed ${ }^{4,30}$.

In the present study patients underwent subtotal colectomy only when the progression of markers was delayed in all segments of the large bowel. If transit in the right part of the colon was normal, partial left-sided colectomy was performed. If transit was delayed only in the rectosigmoid region, anorectal outlet obstruction was diagnosed and no colectomy was performed. The results of this prospective study indicate that the clinical outcome is similar in the two groups undergoing resection.

The present results seem less favourable than those reported by others. From our point of view, evaluation of clinical outcome should be based on four criteria: recurrent constipation, severe abdominal discomfort, disabling diarrhoea and faecal incontinence (Table 2). Other studies indicate that subtotal colectomy usually produces improvement as defined by more frequent stools. However, many patients continue to have abdominal pain, bloating, nausea and vomiting. Furthermore, diarrhoea and faecal incontinence also decrease quality of life considerably and should be taken into account. In only three studies have these criteria been evaluated $^{20,27,28}$; the present results are similar to those obtained in these.

To determine the final outcome after surgical treatment of slow transit constipation long-term follow-up is recommended by most authors. In this study, however, it was found that constipation recurred within the first 12 months in 80 per cent of the recurrences and severe abdominal discomfort recurred within the first 15 months in 90 per cent of those affected. This suggests that the benefit of surgery tends to be maintained, which is supported by the findings of Kamm et al. ${ }^{27}$.

In our opinion, segmental colonic transit time studies are a useful tool to select patients with slow transit constipation for partial left-sided or subtotal colectomy. Because the clinical outcome of partial left-sided colectomy is similar to that of subtotal colectomy such limited resection should be taken into account if progression of markers is normal in the right part of the colon. Because of the moderate functional results, both procedures should be performed with prudence.

\section{References}

1 Preston DM, Lennard-Jones JE. Severe chronic constipation of young women: 'idiopathic slow transit constipation'. Gut 1986; 27: 41-8.

2 Preston DM, Hawley PR, Lennard-Jones JE, Todd IP. Results of colectomy for severe idiopathic constipation in women (Arbuthnot Lane's disease). Br J Surg 1984; 71: 547-52.

3 Gasslander T, Larsson J, Wetterfors J. Experience of surgical treatment for chronic constipation. Acta Chirurgica Scandinavica 1987; 153: 553-6.

4 Zenilman ME, Dunnegan DL, Soper NJ, Becker JM. Successful surgical treatment of idiopathic colonic dysmotility. The role of preoperative evaluation of coloanal motor function. Arch Surg 1989; 124: 947-51.

5 Schouten WR, Gordon PH. Physiology. In: Gordon PH, Nivatvongs S, eds. Principles and Practice of Surgery for the Colon, Rectum and Anus. St Louis, Missouri: Quality Medical Publishing, 1992: 39-79.

6 Catchpole BN. Motor pattern of the left colon before and after surgery for rectal cancer: possible implications in other disorders. Gut 1988; 29: 624-30.

7 MacDonagh R, Sun WM, Thomas DG, Smallwood R, Read NW. Anorectal function in patients with complete supraconal spinal cord lesions. Gut 1992; 33: 1532-8.

8 Martelli H, Devroede G, Arhan P, Duguay C. Mechanisms of idiopathic constipation: outlet obstruction. Gastroenterology 1978; 75: 623-31.

9 Kuijpers HC. Application of the colorectal laboratory in diagnosis and treatment of functional constipation. Dis Colon Rectum 1990; 33: 35-9.

10 Stivland T, Camilleri M, Vassallo $\mathrm{M}$ et al. Scintigraphic measurement of regional gut transit in idiopathic constipation. Gastroenterology 1991; 101; 107-15.

11 Arhan P, Devroede G, Jehannin B et al. Segmental colonic transit time. Dis Colon Rectum 1981; 24: 625-9.

12 Arbuthnot Lane W. Remarks on the results of the operative treatment of chronic constipation. BMJ 1908; i: 126-30.

13 Henley FA. Pelvic colectomy for obstinate constipation. Proc $R$ Soc Med 1967; 60: 806-7. 
14 Mahorner H. Surgery for intractable constipation. Am Surg 1970; 36: 119-23.

15 Aminev AM, Golovachev VL, Veretenkov VI. The surgical management of intestinal stasis. Am J Proctol 1976; 27: $37-41$.

16 Hughes ESR, McDermott FT, Johnson WR, Polglase AL. Surgery for constipation. Aust $N Z$ J Surg 1981; 51: 144-8.

17 Fasth S, Hedlund H, Svaninger G, Öresland T, Hultén L. Functional results after subtotal colectomy and caecorectal anastomosis. Acta Chirurgica Scandinavica 1983; 149: 623-7.

18 Klatt GR. Role of subtotal colectomy in the treatment of incapacitating constipation. Am J Surg 1983; 145: 623-5.

19 Gilbert KP, Lewis FG, Billingham RP, Sanderson E. Surgical treatment of constipation. West J Med 1984; 140: 569-72.

20 Leon SH, Krishnamurthy S, Schuffler MD. Subtotal colectomy for severe idiopathic constipation. A follow-up study of 13 patients. Dig Dis Sci 1987; 32; 1249-54.

21 Keighley MRB, Shouler P. Outlet syndrome: is there a surgical option? J R Soc Med 1984; 77: 559-63.

22 Roe AM, Bartolo DCC, Mortensen NJMcC. Diagnosis and surgical management of intractable constipation. Br J Surg 1986; 73: 854-61.

23 Beck DE, Jagelman DG, Fazio VW. The surgery of idiopathic constipation. Gastroenterol Clin North Am 1987; 16: 143-56.

24 Walsh PV, Peebles-Brown DA, Watkinson G. Colectomy for slow transit constipation. Ann $R$ Coll Surg Engl 1987; 69: $71-5$.

25 Akervall S, Fasth S, Nordgren S, Öresland T, Hultén L. The functional results after colectomy and ileorectal anastomosis for severe constipation (Arbuthnot Lane's disease) as related to rectal sensory function. Int $J$ Colorectal Dis 1988; 3: 96-101.

26 Vasilevsky CA, Nemer FD, Balcos EG, Christenson CE, Goldberg SM. Is subtotal colectomy a viable option in the management of chronic constipation? Dis Colon Rectum 1988; 31: 679-81.

27 Kamm MA, Hawley PR, Lennard-Jones JE. Outcome of colectomy for severe idiopathic constipation. Gut 1988; 29: 969-73.

28 Yoshioka K, Keighley MRB. Clinical results of colectomy for severe constipation. Br J Surg 1989; 76: 600-4.

29 Kamm MA, van der Sijp JRM, Hawley PR, Philips RKS, Lennard-Jones JE. Left hemicolectomy with rectal excision for severe idiopathic constipation. Int J Colorectal Dis 1991; 6: 49-51.

30 Pemberton JH, Rath DM, Ilstrup DM. Evaluation and surgical treatment of severe chronic constipation. Ann Surg 1991; 214: 403-13.

31 Wexner SD, Daniel N, Jagelman DG. Colectomy for constipation: physiologic investigation is the key to success. Dis Colon Rectum 1991; 34: 851-6.

32 Rex DK, Lappas JC, Goulet RC, Madura JA. Selection of constipated patients as subtotal colectomy candidates. $J$ Clin Gastroenterol 1992; 15: 212-17.

33 Bassotti G, Betti C, Pelli MA, Morelli A. Extensive investigation on colonic motility with pharmacological testing is useful for selecting surgical options in patients with inertia colica. Am J Gastroenterol 1992; 87; 143-7.

34 Sunderland GT, Poon FW, Lauder J, Finlay IG. Videoproctography in selecting patients with constipation for colectomy. Dis Colon Rectum 1992; 35: 235-7.

35 Varma JS, Smith AN. Neurophysiological dysfunction in young women with intractable constipation. Gut 1988; 29: 963-8.

36 MacDonald A, Shearer M, Paterson PJ, Finlay IG. Relationship between outlet obstruction constipation and obstructed urinary flow. Br J Surg 1991; 78: 693-5.

37 Hinton JM, Lennard-Jones JE, Young AC. A new method for studying gut transit times using radioopaque markers. Gut 1969; 10: 842-7.

38 Metcalf AM, Philips SF, Zinsmeister AR, MacCarty RL, Beart RW, Wolff BG. Simplified assessment of segmental colonic transit. Gastroenterology 1987; 92: 40-7.

39 Cummings JH, Jenkins DJA, Wiggins HS. Measurement of the mean transit time of dietary residue through the human gut. Gut 1976; 17: 210-18.

40 Van der Sijp JRM, Kamm MA, Nightingale JMD et al. Radioisotope determination of regional colonic transit in severe constipation: comparison with radio-opaque markers. Gut 1993; 34: 402-8. 